Are There Dynamic Gains from a Poor-Area

Jyotsna Jalan

Martin Ravallion

The World Bank

Policy Research Department

Poverty and Human Resources Division

December 1996 
Policy Research Working Paper 1695

\section{Summary findings}

Poor-area development programs - in which the government transfers extra resources to unusually poor areas - have been widely used in efforts to fight poverty. There has been some research on such programs but we know little about their impact on household living standards over time.

Jalan and Ravallion address the issue for a sizable poor-area development program in rural China. China's program had a significant impact on rural living standards in the targeted areas of the sample. But this fact was not evident by comparing the growth rates of consumption in targeted areas with growth rates elsewhere. A simple comparison of the growth rates suggested that although the program was successfully targeted to poorer areas, it did nothing to improve their position relative to other areas. There were strong signs of unconditional (absolute and relative) divergence over time between the areas covered by the program and those that were not.

There are two reasons why these signs of unconditional divergence are so misleading about program benefits. First, there are external effects of initial area characteristics on consumption growth at the bousehold level. Second, whether an area is targeted appears to depend heavily on those same area characteristics. There is a large omitted-variable bias in assessments of program impact that do not take account of differing local conditions.

Jalan and Rayalion use the Generalized Method of Moments to get a consistent estimate of a dynamic model of consumption growth at the farm-household level. Growth is a function of whether tine county of residence is included in the program, plus community and housebold level nitial conditions and covariate shocks to farm yields.

The consumption-growth model suggests that households living in areas targeted by the program had a higher rate of consumption growth than one would have otherwise expected. Without the program, the initial conditions in those aticas appear to have been so unfavorable that they would have seen a decline in average living standards over the period studied. The gains were enough to prevent an absoluce decline, but not enough over five years to reverse the strong underlying divergent tendencies in the rural economy.

This paper - a product of the Poverty and Human Resources. Division, Yolicy Research Depattment - is part of a larger effort in the department to evaluate the welfare impact of public programs. The study was funded by the Bank's Research Support Budget under the research project "Policies for Poor Areas" (RPO 678-79). Copies of the paper are available free from the World Bank, 1818 H Street NW, Washington, DC 20433. Please contact Ardrea Ramizez, room N8-036, telephone 202-458-5734, fax 202-522-1153, Internet address mravalion@worldbank.org. December 1996. (29 pages)

The Policy Research Working Paper Sertes disseminates the findings of work in prograss to encouthge the exchange of ideas about development issues. An objective of the series is to get the findings ont quickly even if the presertations are less than fully polished. The papers carry the names of the authors and should be cited accordingly. The findings, interpretations, and conclusions expressed in this

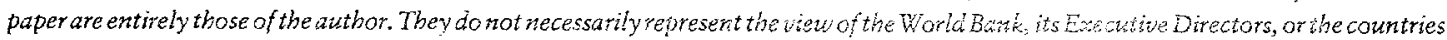
they represent. 


\title{
Are there dynamic gains from a poor-area
}

\section{development program?}

\author{
Jyotsna Jalan and Martin Ravallion* \\ Policy Research Department, World Bank \\ 1818 H Street NW, Washington DC, 20043
}

* The authors acknowledge the generous assistance and advice provided by staff of China's State Statistical Bureau in Beijing and at various provincial and county offices. They have also benefitted from discussions with various staff of the State Council Leading Group for Economic Development of Poor Areas. Helpful comments on an earlier draft were received from Shaohua Chen, Emmanuel Jimenez, Stephen Howes, Dominique van de Walle, Michael Walton and participants at presentations at the State Statistical Bureau, Beijing, the Chinese University of Hong Kong, the North-American Winter Econometric Society meetings 1996, the Tinbergen Institute, Amsterdam, and the University of Notre-Dame de la Paix Namur, Belgium. Stephen Howes provided some of the county-level data used here, and Shaohua Chen has helped in setting up the data set. These are the views of the authors, and need not reflect those of the World Bank. The financial support of the Bank's Research Committee (RPO 678-79) is gratefully acknowledged. 
Poor-area development programs-whereby the government Iransfers extra resources to areas which are deemed to be unusually poor-have been widely used in public efforts to fight poverty. While there has been some research on their performance in targeting poor areas and poor people, ${ }^{1}$ we know far less about their impact on household living standards over time. Are such programs merely short-term palliatives, or do they yield longer-term gains to poor areas?

The net impacts are unclear on a priori grounds. There are likely dead-weight losses, such as extra administrative costs and foregone incomes of participants. Or the extra public resources may displace other funds for investment with little or no net gain. Furthermore, quantifying the gains from a poor-area program is complicated by the fact that a government's choice of the areas covered could well be influenced by outcome indicators subsequently used in the evaluation of the program or on unobserved (by the researcher) determinants of the indicators themselves. ${ }^{2}$

Why does a poor area exist? The area may have suffered a shock. But it appears to be at least as common to find areas that are persistently poor over a long time. Theories of economic growth offer some clues as to why this may happen. The standard Solow-Swan "exogenous" growth model suggests that the answer lies in persistent spatial differences in technologies or the policy environment, in the absence of which the lagging areas will eventually catch up even without factor mobility. A somewhat richer set of explanations for poor areas can be found in recent "endogenous

1 See Datt and Ravallion (1993) for India and Ravallion (1993) for Indonesia. Lipton and Ravallion (1995, section 6) survey past research on these programs and other direct: interventions common in developing countries.

2 On the potential bias in evaluation when program placement is endogenous see Rosenzweig and Wolpin (1986), Pitt, Rosenzweig and Gibbons (1993) and Besley and Case (1994). The main difference between the problem studied by these papers and that studied here is that we are concerned with identifying dynamic impacts at the household level in a situation in which program placement can be taken to be exogenous to household decision making. 
growth models". 3 These predict that growth rates will also vary with initial conditions; factor mobility will then be crucial to the prospects for poor areas. Persistently poor areas can thus arise from inequalities in community endowments. ${ }^{4}$ Restrictions on mobility are not essential for that outcome, but they make it more likely. Living in a poor area can thus mean that a household is more likely to be poor now and in the future ceteris paribus.

This explanation for poor areas has a potentially important implication for assessing the dynamic gains from area-specific interventions to reduce poverty. We will argue that farm-household locations can be treated as exogenous in this setting, and we assume that no household is powerful enough to have its locality declared poor. Thus living in a designated poor area can be taken as exogenous to household choices. However, the existence of spatial externalities may well entail that the growth path of future household living standards is dependent on the same community characteristics which influence the public decision to declare the community poor. The problem is essentially one of omitted-variable bias when there is state-dependence in the growth process. ${ }^{5}$ For example, a low endowment of local public goods may simultaneously induce a lower rate of growth and a higher probability of the community being declared poor. Unless this is accounted for, the value to households of living in an area which is targeted under the program will be underestimated.

We address the above issues in the context of the sizable poor-area development program found in rural China since the mid-1980s, though the approach we offer is more widely applicable. The method we propose entails consistently estimating a dynamic model of consumption growth at

\footnotetext{
3 For an exposition of both exogenous and endogenous growth models see Barro and Sala-i-Martin (1995).

4 Models of how this can happen have been provided by Durlauf (1992) and Benabou (1994).

5 By "state dependence" we mean that initial conditions-as represented by a dynamic system's initial state vector-influence the future evolution of that system.
} 
the household level using panel data. The model allows us to test the dynamic impact on households of whether or not the area of residence is covered by the poor-area program, controlling for initial conditions at both household and community level. ${ }^{6}$

Models in which the first difference of a variable depends on initial conditions have been popular in recent literature testing endogenous growth models on country- and regional-level data sets. ${ }^{7}$ There are a number of differences in our approach, some less important than others. Here we are analyzing farm households who jointly produce and consume, rather than economies in which separate consumers and producers interact through trade. But this is largely a matter of interpretation; the separation of an economy into households (which consume) and firms (which produce) is not essential in standard growth models. ${ }^{8}$ In the present setting, the farm-household can be thought of as a small open economy, trading with those around it.

One advantage of using the household as the unit of observation is that one can identify external effects of non-market community goods on production processes at household level which are otherwise lost in aggregation. Another implication is that standard growth-theoretic models derive testable propositions about the steady state of an economy; in our setting one can allow for deviations between the current year's data and the underlying model's steady-state solution, due to shocks and/or adjustment costs. We thus obtain a more powerful test of the impact of initial conditions on the evolution of living standards than is possible by only modelling the long-run

6 While it is common to model the variables of interest in first-difference form, or as deviations from their time means, this is typically done in the context of a static model in levels, for which the time slope is a constant and there are unobserved fixed effects. Clearly such a formulation is of little interest here since it does not allow initial conditions to affect the growth path of the variable of interest.

7 For references and discussion see Sala-i-Martin (1994) and Barro and Sala-i-Martin (1995).

8 Standard endogenous growth models postulate separate households and firms, but an equivalent formulation is possible in which households both consume and produce (Barro and Sala-I-Martin, 1995, Chapter 2). 
average growth rates. By using a Generalized Method of Moments estimator we are able to obtain consistent estimates of a dynamic growth model on panel data under relatively weak assumptions.

The following section presents descriptive results which motivate the later analysis. We use household data for four provinces of southern China 1985-90, supplemented by interviews with local administrators and households in fields trips during 1994-95. ${ }^{9}$ We find that an unconditional comparison of areas in southern China covered by the poor-area program and those not covered suggests that the program has done nothing to help poor areas catch up with other areas-the program benefits seem to have vanished. Section 3 aims to solve this mystery using a micro-model of consumption growth which controls for both household-level and community initial conditions. Our conclusions can be found in section 4.

\section{The mystery of the vanishing program benefits}

\subsection{Background}

The impressive economic growth in China as a whole since economic reforms in the late 1970s has been quite unbalanced regionally. As a consequence progress in reducing poverty has been far greater in some areas than others. ${ }^{10}$ It can be argued that with greater mobility of the factors of production, the lagging areas will start to catch up. However, labor in China still appears to be quite immobile, and there is a seemingly wide-spread perception that the more profitable areas

\footnotetext{
9 One or both of the authors visited a total of eight counties with at least two poor counties in each of the three poor provinces (Guangxi, Guizhou and Yunnan).

10 For example, Howes and Hussain (1994) report that the poorest $5 \%$ of rural China's 2200 counties saw near-zero growth in average income over 1985-91. For other evidence on China's regional disparities see Lyons (1991), Tsui (1991), World Bank (1992), Knight and Song (1993), Rozelle (1994) and Howes and Hussain (1994). Data problems have confounded past empirical work, though Chen and Ravallion (1995) find that (for southern China) the qualitative conclusion of rising disparities and higher poverty in some regions persists once one corrects for what seem to be the main problems.
} 
for private investment have tended to be the better-off ones, with the effect that regional inequalities have increased in the process of liberalizing private financial flows. The local (county-level) administrators in poor counties of southern China we interviewed said it was rare for these areas to receive private investment from outside the county.

As a response to concerns about lagging poor areas, the central Government introduced an anti-poverty program in 1986 which declared that 272 counties were "national-poor counties", and targeted substantial aid to those counties. The extra aid took the form of subsidized credit for village-level projects (provided at well below market rates of interest), funding for public works projects (under "food-for-work" programs), and direct budgetary support to the county government. This national poor area program is the main direct intervention in the central government's current poverty reduction policy (Leading Group, 1989; World Bank, 1992; Riskin, 1994). At the province level, a number of additional counties were identified as "provincial-poor" on relative-poverty criteria, and also received extra aid from the provincial government, though these schemes often operate quite separately in their funding and implementation.

The program is unlikely to benefit poor people in areas not covered, and there may well be leakage to the non-poor in areas covered. Even with sizable regional disparities in average incomes, the twin problems of imperfect coverage of the poor, and leakage to the non-poor, can greatly dull the overall impact on poverty. ${ }^{11}$ Though we throw some light on the targeting performance of China's poor area program, that is not our main concern here. Instead we focus on assessing the welfare gains over time in targeted areas.

1 In the four provinces of China which we study in this paper over the period 1985-90, roughly half of the poor (using the definition in Chen and Ravallion, 1995) did not live in counties which were declared poor either nationally or provincially. 
Why might a poor area program induce a higher rate of consumption growth in the targeted area? The extra resources made available under China's program were not, of course, disbursed as a lump-sum in 1986 , but rather as an annual flow of monies beginning in that year. Impacts on the current rates of consumption growth could then arise in two ways: the first is that the investments under the program yield current returns, and the second is that--even if there was no net gain in investment, and the program acts like a pure consumption transfer-a rising flow of extra monies over time will entail higher current consumption growth.

In discussions with us, administrators emphasized the program's investment role; indeed, explicit use of funds for current consumption purposes is not allowed. All of the specific projects funded under the program mentioned in our discussions were investment projects. ${ }^{12}$ Furthermore, the real resource flow in the aggregate from the national program was reasonably constant over the period 1986-90 (at about Yuan 4.0 billion per year at 1985 prices). These observations lend some support to the first explanation of any consumption-growth gains in the program areas.

\subsection{The setting for our analysis}

We shall examine program impacts in the four contiguous provinces of Guangxi, Yunnan, Guizhou and Guangdong, spanning the southern part of the country, between the South China Sea and the borders with Myanmar, Laos and Vietnam. Three of the provinces (Guangxi, Yunnan and Guizhou) are in South-West China, widely regarded as one of the poorest regions of the country. The fourth is the relatively affluent neighboring coastal province of Guangdong.

12 Oft mentioned projects included irrigation, land flattening, land conservation, planting fruit trees, livestock, food processing, and constructing and maintaining local roads. 
Data on the counties within these provinces were gathered from the county yearbooks 198087 , and from the 1982 census data. ${ }^{13}$ We also know which counties within each province come under either of the national or provincial poor-area development programs. However, data on precisely how much is spent on each county are not available.

According to the program's administrators, the targeted counties were selected according to their inferior socio-economic conditions (Leading Group, 1989). This assessment appears to have been based entirely on administrative and statistical data (though one cannot rule out the possibility that administrative records at local level may have been manipulated to help assure selection by the center). Our data do suggest that there was effective targeting to poor areas for the 44 program counties among the 131 counties in our sample provinces. Gross rural social product per capita in the declared poor counties was Yuan 351.93 (standard deviation: 101.38) while in the other counties it was 626.94 (standard deviation: 524.06). Though the cultivated area per capita was virtually the same in the two groups (approximately 1300 square meters), the grain yield in the program counties was only two-thirds of that observed for the other counties, and the difference between the average yields was statistically significant. The infant mortality rate was 53.86 per 1,000 live births in the declared poor counties compared with 39.08 per 1,000 live births in the non-program counties and again the difference in the averages was statistically significant. Similarly, the proportion of illiterates in the $15^{+}$population was higher in the program areas $(45.28 \%)$ relative to others (32.95\%). Finally, disaggregating the program counties into those covered under the national program and those under provincial programs, indicates that the former counties are worse off by

13 While the county yearbooks cover rural areas, the census county data does not separate rural and urban areas. However, given that the objective of including the county characteristics is to control for the initial level of progress in a particular county relative to another, the aggregate county indicators should be reliable proxies for the differences in socio-economic indicators across the counties. 
all the above measures. But the differences are generally small, and even the "province-poor" counties are appreciably poorer than counties not covered under the program.

\subsection{Looking for the benefits at household-level}

In field trips during 1994-95, one or both authors had informal, loosely structured, interviews with about 25 poor households in a number of poor counties in the study area. Amongst the questions we asked was whether or not the household had seen any improvement in its standard of living over the last 10 years. This is a highly subjective question and there is clearly sampleselection bias, so the answers cannot substitute for good quantitative data for a random sample. However, we were struck by how often the answer was "little or no gain", and that was consistent with their meager dwellings and clothing. While there was little sign of chronic hunger, there were signs of persistent poverty. Granted there have been impressive gains in rural China as a whole since reforms began in the late 70's (World Bank, 1992), but it is believable that this process has left many of the poorest behind. (We also visited a number of better-off households who had seen real gains since then.) The signs we saw of both absolute and relative stagnation for the poorest decile or so in rural areas of southwest China are consistent with the analysis of trends in poverty measures based on sample data for the study area (Chen and Ravallion, 1995).

Since a substantial effort appears to have been made to raise living standards in poor areas of this region since the mid-1980s, the above qualitative observations suggest that either the program has failed, or it has for the most part only succeeded in preventing decline. Our interviews with poor households also suggested some factors putting downward pressure on living standards in these areas, including population pressure on limited land which is of poor quality and environmentally 
fragile, and cultivated under conditions of stagnant traditional technologies. ${ }^{14}$ It is possible that the program has prevented rising poverty.

To test that conjecture more rigorously, we shall use a balanced panel of observations on 6,651 households for each of six years, 1985-90. The panel is a new data set constructed for this purpose, from China's Rural Household Survey (RHS). The Appendix describes the data further.

Table 1 gives mean expenditures by year, stratified by whether or not the county of residence was declared poor in 1986. Figure 1 plots these consumptions. Counties declared poor were poorer on average in all six years, and the gap between targeted counties and others actually grew over time, both absolutely and relatively. While in 1985 , mean consumption per capita in the national poor counties was $76 \%$ of that in counties not declared poor, the ratio had fallen to $70 \%$ by 1990 .

Looking at Figure 1 it is very hard to see where the extra monies under the program have gone. There was a $3.0 \%$ gain in average consumption in national-poor areas in the year following the introduction of the program, but this had largely dissipated by 1990 . There was little increase in average consumption in the provincial-poor areas over the period.

These aggregates hide a marked regional difference between coastal and inland areas. None of the households in our Guangdong sample belong to national poor counties. Moreover, the average household consumption per capita in the declared-poor counties of Guangdong are higher than even those for the non-poor counties of the other three provinces (Table 2). The relative poverty criteria applied at province level have clearly diluted overall targeting performance. The unconditional rate of growth of consumption per capita of the targeted counties in Guangdong is also higher (between 1985-90, mean real consumption increased by $21 \%$ ) than observed for the excluded counties of the

14 While fertility has fallen considerably in China this has been less pronounced in poor rural areas, particularly amongst the national minorities (which are in fact a majority of the rural population in much of southwest China.) 
other three provinces. Also the difference in average consumption per capita between the national poor and the province poor counties vanishes once we exclude Guangdong. However, divergence is still evident in Table 2; excluding Guangdong, average consumption decreased by $4 \%$ over 1985 90 in areas declared poor, but increased by $3.2 \%$ elsewhere.

So these descriptive results suggest that while the program did select poorer counties, it did nothing to help them catch up. However, before accepting this conclusion, we must first establish that the growth path in those counties which were not covered by the program is the relevant counter-factual for evaluating the impact of the program. If there are divergent tendencies in the regional economy - as may well be the case in present-day rural China-then it can be argued that initially poorer counties would have grown at an even slower rate if not for the poor-area development program. Next we test that conjecture.

\section{$3 \quad$ The mystery solved?}

State dependence in the growth process has implications for assessing the dynamic gains from a poor-area program. Poor areas may have higher growth through a process of convergence, so that we overestimate the return to being covered under the program by simply comparing growth rates in targeted areas with those elsewhere. Or there may be divergence, in which case the test will underestimate the value of being targeted. Thus, even when living in an area declared poor can be taken as exogenous at the household level, there is still a selection bias in assessing household-level impacts over time. The only way around this problem is to find a method of controlling for the initial conditions which create the troublesome state dependence. ${ }^{15}$

15 This is an example of the general problem of selection bias in program evaluation; for discussion of this problem and corrective actions see Barnow et al., (1980) and Heckman and Robb (1985). 


\subsection{A micro-econometric model of consumption growth}

A fully-specified theoretical model capable of motivating our empirical analysis can be formulated by a re-interpretation of the Romer (1986) model of endogenous growth under increasing returns to scale through externalities. ${ }^{16}$ Analogously to the role of firm-specific knowledge and external (economy-wide) knowledge in Romer's model, one can conjecture that output of the farm household is a concave function of various privately-provided infuts, but that output also depends positively on the level of community capital. On fully accounting, for all private inputs (all profits being reckoned as payments for those inputs), there will then be constant returns to scale to the privately provided inputs, but increasing returns to scale for overall inputs, including community capital. With the farm-household maximizing an inter-temporal utility sum-with instantaneous utility depending on current consumption, which must be partly forgone to assure future output-one can derive an endogenous consumption growth rate which depend on the initial endowments of both private capital and community capital, as well as preference and production parameters. With this re-interpretation, the results on existence and welfare properties of equilibrium in Romer (1986) can be applied to the present problem.

This type of theoretical model is consistent with simultaneously convergent effects with respect to private capital and divergent effects with respect to community capital; a higher private capital stock will entail a lower marginal product of private capital and, hence, lower consumption growth in equilibrium, while a higher stock of community capital will entail higher marginal product of private capital and higher growth. In more general formulations, the direction of the effects of initial conditions will probably be more difficult to predict on a priori grounds, and will depend on

\footnotetext{
16 Also see Lucas (1988). For theoretical expositions of this type of growth model see Hammond
} and Rodriguez-Clare (1993), and Barro and Sala-i-Martin (1995). 
(inter-alia) how well markets work (credit market imperfections, for example, can entail that liquidity-constrained households cannot realize the same growth potential as others) and the politicaleconomy of local public policy (it has been argued that higher initial inequality, for example, may promote policy choices which inhibit growth). ${ }^{17}$ However, the essential dependence of householdlevel growth rates on both internal and external initial conditions appears likely to hold in all except rather special cases.

In carrying such a formulation to data, it would also be unrealistic to assume that the growth rate actually observed at any date is the equilibrium (steady state) value predicted by initial conditions alone. Here we allow short-run divergence from the steady state by postulating an autoregressive distributed lag structure for the growth process, augmented for exogenous shocks and unobserved effects. On introducing dynamics and both time-invariant and time-varying unobserved effects, the model we estimate is (in time-series parlance) a modified $\mathrm{AD}(1,1)$ (autoregressive distributed lag of order 1) model of the form (in levels):

$$
\ln \mathrm{c}_{\mathrm{it}}=\alpha_{\mathrm{o}}+\alpha_{1} \cdot \mathrm{t}+\beta \ln \mathrm{c}_{\mathrm{it}-1}+\gamma_{0} \mathbf{x}_{\mathrm{it}}+\gamma_{\mathrm{i}} \mathbf{x}_{\mathrm{it}-1}+\delta_{1} \mathrm{np}_{\mathrm{i}} \cdot \mathrm{t}+\delta_{2} \mathrm{pp}_{\mathrm{i}} \cdot \mathrm{t}+\boldsymbol{\theta}^{\prime} \mathbf{z}_{\mathrm{i}} \cdot \mathrm{t}+\eta_{\mathrm{i}}+\mathrm{u}_{\mathrm{it}}
$$

for household $\mathrm{i}(=1, \ldots, N)$ at date $t(=1, . . T)$, where $c_{i t}$ is consumption by $i$ at date $t, x_{i t}$ is a $(1 \times k)$ vector of time-varying explanatory variables, $\mathrm{np}_{\mathrm{i}}$ is the dummy for the national poor county, $\mathrm{pp}_{\mathrm{i}}$ is the dummy for the provincial poor county, $\mathbf{z}_{\mathrm{i}}$ is a $\mathrm{p}$-dimensional vector of other initial conditions, and $\eta_{\mathrm{i}}$ is a time-invariant household-level fixed effect. ${ }^{18}$ The vector $\mathbf{z}_{\mathrm{i}}$ comprises both county-

17 For a review of the arguments and evidence on such effects see Bruno et al., (1995).

$18 \mathrm{An} \mathrm{AD}(1,1)$ model is chosen over an alternative model with a longer lag structure because the Wald test on the second lag coefficient is not significant. 
specific factors (initial values of community capital) and household-specific characteristics (initial values of private capital).

The problem of estimating this model is different from the usual "within" estimator for panel data. It is known that the ordinary least squares estimator of an autoregressive fixed effects model is not consistent for a typical panel where the number of periods is small and where the asymptotics are driven by the number of cross-sections going to infinity (Hsiao, 1986). The inconsistency arises because of the potential correlation between the lagged endogenous variables and the residuals in the transformed model. ${ }^{19}$ Instead we use the Generalized Method of Moments (GMM) technique proposed by Arellano and Bond (1991) to estimate equation (1).

Notice that, unlike the standard $\mathrm{AD}(1,1)$ model, the error term in (1) has two components: an unobserved individual specific time-invariant fixed effect, $\eta_{\mathrm{i}}$, and the standard innovation error term, $u_{i t}$. We assume that the unobserved individual specific effect $\eta_{i}$ is correlated with the regressors, i.e., $E\left(\eta_{i} z_{i}\right), E\left(\eta_{i} x_{i}\right)$, and $E\left(\eta_{i} l n c_{i t-1}\right)$ are non-zero. ${ }^{20}$ The error $u_{i t}$ is serially uncorrelated and thus satisfies the orthogonality conditions:

$$
\mathrm{E}\left(\ln \mathrm{c}_{\mathrm{is}} \mathrm{u}_{\mathrm{i}}\right)=\mathrm{E}\left(\mathrm{x}_{\mathrm{is}} \mathrm{u}_{\mathrm{it}}\right)=0 \text { for } \mathrm{s} \ll \mathrm{t}
$$

These conditions ensure that lagged values of $l n c_{i t}$ and $x_{i t}$ can be used as instruments. In order to get consistent estimators, the unobserved fixed effects $\eta_{\mathrm{i}}$ need to be eliminated. This is done by taking the first differences of (1) to obtain the transformed model:

19 The inconsistency is of order (1/T) (where $\mathrm{T}$ is the number of time periods) and hence if the number of periods is large enough, the asymptotic bias of the least squares estimator will tend to zero. However, as mentioned earlier, in our case, the number of time periods is finite and short, and thus we cannot escape from the asymptotic bias created by the least squares dummy variable models.

20 Bhargava and Sargan (1982) estimate a dynamic random effects model where they assume that at least some of the time-varying variables are uncorrelated with the unobserved individual specific effect. 


$$
\Delta l n c_{\mathrm{it}}=\alpha_{1}+\beta \Delta i n \mathrm{c}_{\mathrm{it}-\mathrm{l}}+\gamma_{0}{ }^{\prime} \Delta \mathrm{x}_{\mathrm{it}}+\gamma_{1}{ }^{\prime} \Delta \mathrm{x}_{\mathrm{it}-1}+\delta_{1} \mathrm{np}_{\mathrm{i}}+\delta_{2} \mathrm{pp}_{\mathrm{i}}+\theta^{\prime} \mathrm{z}_{\mathrm{i}}+\Delta \mathrm{u}_{\mathrm{it}}
$$

GMM methods are used to estimate the parameters in equation (3). Given that the $u_{\mathrm{it}}{ }^{\text {'s }}$ are serially uncorrelated, the GMM estimator is the most efficient one within the class of instrumental variable (IV) estimators. In estimating (3), $l n c_{\mathrm{it}-2}$ or higher lagged values (wherever feasible) are valid instrumental variables. Thus typically the coefficient estimates of the parameter vector $v=$ $\left(\alpha_{1}, \beta, \gamma_{0}, \gamma_{1}, \delta_{1}, \delta_{2}, \theta\right)$ are given by:

$$
\hat{\nu}=\left(\mathbf{q}^{\prime} \mathbf{w} \mathbf{a}_{\mathbf{n}} \mathbf{w}^{\prime} \mathbf{q}\right)^{-1}\left(\mathbf{q}^{\prime} \mathbf{w} \mathbf{a}_{\mathbf{n}} \mathbf{w}^{\prime} \Delta \mathbf{c}\right)
$$

where $\mathbf{q}=\left[\mathbf{e}, \Delta \mathbf{c}_{-\mathrm{p}}, \Delta \mathbf{x}_{\mathrm{s}}, \mathbf{n p}, \mathbf{p p}, \mathbf{z}\right]^{\prime}$, is the set of regressors with $\mathbf{e}^{\prime}$ a vector of ones, $\mathbf{w}$ is the matrix of instrumental variables, $a_{n}$ is the weighting matrix, $(p, s)$ are the appropriate lags on the time-varying instruments, and $\Delta \mathrm{c}$ is the (NTx1) vector of the first differences of log consumption. From Hansen (1982) it follows that the optimal choice of $\mathbf{a}_{\mathbf{n}}$ ("optimal" in the sense of giving the most efficient estimator asymptotically) is proportional to the inverse of the asymptotic covariance matrix. ${ }^{21}$ Heteroscedastic consistent standard errors are computed using the residuals from a firststage regression to correct for any kind of general heteroscedasticity.

Inferences on the estimated parameter vector $\hat{\nu}$ are appropriate provided the moment conditions used are valid. Sargan's (1958) and Hansen's (1982) over-identifying restrictions (chisquare) test is implemented to test that the over-identifying restrictions are consistent with the data. In addition, a second-order serial correlation test (the test-statistic for this test is normally distributed)

21 In the just-identified case (i.e. in the case where the number of moment conditions are exactly equal to the number of parameters to be estimated), the parameter estimates do not depend on the weighting matrix and hence the choice of $a_{n}$ is redundant. 
is constructed given that the consistency of the GMM estimators for the first differenced model depends on the assumption that $\mathrm{E}\left(\Delta \mathrm{u}_{\mathrm{it}} \Delta \mathrm{u}_{\mathrm{it}-2}\right)=0 .{ }^{22}$

In estimating this model we will assume that all initial area characteristics $\left(n p_{i}, p_{i}\right.$ and $z_{i}$ ) are exogenous to the household-level growth process. The main way in which this may fail to hold is through mobility, whereby households choose their area characterisics. In rural China there have been long-standing restrictions on mobility. Since the $1950 \mathrm{~s}$, China has had laws which restrict access to employment and public services according to one's officially registered place of residence. ${ }^{23}$ From our discussions with rural households and others familiar with the setting it appears to be very unusual for a whole family to move on its own accord; the mobility that does occur involves a single worker within the household.

\subsection{Estimates of the model and implications for program performance}

The most important time-varying exogenous variables in an under-developed rural setting are agro-climatic conditions. We measure these by the average grain yield per unit area at the county level. Change in demographics within the household is proxied by change in household size (though the current year's household size is treated as endogenous). Province-specific year dummies are also included to pick-up province-specific shocks.

According to the program's administrators, the targeted counties are characterized by lower socio-economic conditions. Given that these characteristics are potentially correlated with a county

22 There may be some first-order serial correlation, i.e., $\mathrm{E}\left(\Delta \mathrm{u}_{\mathrm{in}} \Delta \mathrm{u}_{\mathrm{it}-1}\right)$ may not be equal to zero since $\Delta \mathrm{u}_{\mathrm{it}}$ are the first differences of serially uncorrelated errors. Alternatively, if $\mathrm{u}_{\mathrm{it}}$ is a random walk, then there should not be any serial correlation in the first differenced $\Delta u_{n}$.

23 These laws were relaxed in the early 1990 s, to allow employment in cities for rural workers. Significant constraints on mobility persist though; registrtaion in urban areas is still difficult and costly to obtain, and unregistered workers have highly restricted access to urban servives (they typically cannot send their children to urban schools, for example). 
being declared poor or not, excluding these variables from our model will lead to an omitted variable bias in the parameters of interest, as discussed in the introduction. The direction of the bias depends on the sign of the partial correlation coefficient between the poor counties and the excluded variables. ${ }^{24}$

To deal with this source of bias, we first estimated a probit model at the county level. Our binary variable takes a value of 1 if it is a declared poor county (either national or provincial poor) and 0 otherwise. Available county characteristics are included as explanatory variables in this probit model. The characteristics included were wealth per capita, fertilizer usage per square kilometer of cultivated area, irrigated area per square kilometer of cultivated area, electricity usage per capita, cultivated area per caita, total population of the county, and agricultural machinery used per square kilometer of the cultivated area. Among the initial county conditions, wealth per capita and fertilizer usage per square $\mathrm{km}$ of cultivated area were signifcant. ${ }^{25}$ We thus used these two variables to proxy for the wide range of county characteristics in the GMM model. Finally, household-level initial wealth per capita was also included, to control for differences in initial capital at the household level (under diminishing marginal returns this should have a negative coefficient).

In Table 3, we report the GMM estimates. The results show that there is divergence in the growth rates insofar as the county initial conditions are concerned, but across households there is convergence. We interpret these results as indicating decreasing returns to "own wealth" at the farmhousehold level, combined with positive effects of "community wealth" on the marginal product of

24 If the partial correlation coefficient between the included and the excluded variable is zero, then the coefficient associated with the included variable will be unbiased, but the variance of the estimated parameter would still be biased, thereby making it impossible to conduct valid inferences on the estimated coefficients.

25 Both variables are sample means from the (roughly one third larger) cross-sectional surveys from which the panel was drawn. The wealth variable is defined as the sum of the values of fixed productive assets, cash, deposits, housing, grain stock, and stock of durables, all at year end. 
own wealth and (hence) consumption growth. There is weakly significant serial dependence in consumption growth, with 0.11 (t-ratio: 1.68 ) of last period's growth rate being transmitted to the current period. Higher current and lagged grain yields at the county level are reflected in higher household-level growth rates. The strength of these effects suggests that households are exposed to sizable uninsured yield risk.

Controlling for initial community and household-level factors, the results in Table 3 indicate that household-level consumption growth rates tend to be significantly higher in counties initially declared poor under the national program. The short-run effect entails a 1.1 percentage point increase in the growth rate of consumption, rising to 1.35 in steady state. However, there is no sign of any significant effect of being targeted under the provincial program.

This is a substantial gain in the rate of growth; indeed, since the actual rate of growth in the national-poor areas was close to zero over the whole period (Figure 1), these results suggest that without the program we would have seen a net contraction of a similar absolute magnitude in the areas designated poor under the national program.

But the resource flow under the program was also substantial. From data provided by the government, we estimate that Yuan 26 per person per year was spent on the program in the national poor areas of our four provinces during the period 1985-90. This comprises the center's outlays on credit, public works and so on, but excludes administration costs, and any local "top-up" funds provided from county resources to augment the center's outlay (such top-up funds appear to be impossible to measure). Our model indicates a $1.1 \%$ per year gain in consumption, representing an average gain in national poor areas of Yuan 3 per person per year over the period. Thus, these calculations suggest that about one fifteenth of the current budgetary outlay is being reflected in 
household consumption in the targeted areas. Assuming that the outlays are solely for investment, the marginal rate of return is $12 \%$.

This could well be an overestimate. For one thing, there are public expenditures on the program which have not been accounted for, as noted above. Also one should also be cautious about interpreting these as "long-run" gains since we may actually be seeing at least partly the direct consumption gains from a rising flow of monies; when the program stops, the gains will stop. As we discussed in section 2, the program is designed to finance investment in poor areas, not consumption directly, though there could well be a degree of fungibility for recipients. Interpreting our results as evidence of long-run gains is also problematic given that we have only five years of data after the program began; although our estimator should be unbiased in even such short panels, it is always hazardous to project too far beyond the sample period. Suffice to say that there is strong evidence here of dynamic gains, though over what period is a more moot point.

\subsection{Further tests}

i) If we are right about the bias arising from ignoring spatial state dependence in assessing dynamic gains at the household level, then our results should change considerably when we drop initial county conditions from the regression. That is what we found. Dropping initial county wealth and fertilizer usage from the regression in Table 3, the dummy variable for national poor counties became highly insignificant (a t-ratio of 0.6 ), while that for provincial poor counties became highly

significant, but negative $\left(\hat{\delta}_{2}=-0.0097\right.$, with a t-ratio of -2.44$)$. This confirms that a large bias can occur in assessments of the gains from poor-area programs which do not take account of how community characteristics can influence household-level outcomes. 
ii) The gain to living in a county covered under the program may vary by characteristics of households. On a priori grounds it is difficult to predict which way such effects would go; on the one hand, poorer households may have more chance of receiving aid through targeting efforts within declared-poor counties; but on the other hand, they may be less well positioned to get a good rate of return to that aid due to lack of complementary assets and skills. We re-estimated the model allowing interaction effects of the dummy variable for "national pcor" counties with initial household wealth included in the unrestricted GMM model. The interaction term was insignificant, indicating no pro-poor targeting.

iii) Possibly there are also indirect impacts on household-level growth rates, via the average grain yield in the county. We tested this by GMM regressions of the log of yield against its own lagged value and county initial wealth. Both the dummy variables for "national poor" and provincial poor" counties were highly insignificant ( $t$-ratios of 0.89 and 0.86 respectively). So there do not appear to have been indirect effects via agricultural productivity.

\section{Conclusions}

China's poor-area development program had a significant impact on rural living standards in the targeted areas of our sample. However, this fact is not evident by comparing the growth rates of consumptions in targeted areas versus others. That comparison suggests that-while the program was successfully targeted to poorer areas-it did nothing to improve their position relative to other areas. Indeed, there are strong signs of unconditional (absolute and relative) divergence over time between the areas covered by the program and those not. There are two reasons why these signs of unconditional divergence are so deceptive about program benefits: firstly, there are external effects of initial area characteristics on consumption growth at the household level, and, secondly, whether 
or not an area is targeted appears to depend heavily on those same area characteristics. Thus there is a large omitted-variable bias in assessments of program impact which do not take account of differing local conditions.

To support these claims, we used the Generalized Method of Moments to obtain a consistent estimate of a model of consumption growth at the farm-household level. Growth is a function of whether or not the county of residence is included in the program, plus community and householdlevel initial conditions and covariate shocks to farm yields. We find that the higher the initial household wealth, the lower the subsequent rate of growth; this is consistent with diminishing returns to own capital. By contrast, the lower the community's initial average wealth, the lower the subsequent rate of household consumption growth ceteris paribus, suggesting that better endowements of community capital raise the marginal returns to investment at the household level.

The consumption-growth model also suggests that households living in areas targeted by the program had a higher rate of consumption growth than one would have otherwise expected. Indeed, without the program, the initial conditions in these areas appear to have been so unfavorable that we would have seen a decline in average living standards over the period. The gains were enough to prevent absolute decline. But they were not enough over the five years to reverse the strong underlying divergent tendencies in the rural economy. 
Appendix: The household-level data

The household panel data set was constructed from China's Rural Household Survey (RHS), conducted by the State Statistical Bureau since 1984. The sampled households were not changed over the period 1985-90, though this fact does not appear to have been previously exploited to form a panel. However, the sample was rotated in 1991, so we cannot construct a longer panel. Constructing the panel from the annual RHS survey data proved to be more difficult than expected since the identifiers could not be relied upon. Relatively stringent criteria were used in defining a panel household, with extensive cross-checks to assure that the same household was being tracked over time. Fortunately, virtually ideal matching variables were available in the financial records, which gave both beginning and end of year balances. The relatively few ties by these criteria could easily be broken using demographic data.

The RHS is an unusually good quality survey in some respects, notably in the care that goes into reducing both sampling and non-sampling errors. A random sample of counties is drawn, and then of villages within counties, and households within villages, and a number of checks indicate that it can be considered representative (Chen and Ravallion, 1996). Sampled households keep a daily record of all transactions, as well as log books on production. Interviewing assistants visit each sampled household every two weeks to check on their progress and collect the data. Checks are made at the county statistical office, with return visits to the households when necessary.

However, there are also some problems in the RHS's valuation and accounting methods, most notably the fact that grain consumption from own production was valued at administrative prices which were below-and progressively diverged from-market prices for grain actually sold. Also the survey processing assigned lumpy expenditures on housing and consumer durables to the current year even though these typically deliver benefits over many years. These problems have been 
corrected in the data set used here, by reprocessing the raw data (Chen and Ravallion, 1996). The value of grain produced by the household but not marketed has been valued at the county median selling-price. And the service flows from housing and consumer durables have been imputed by amortizing the asset values. All expenditures have been converted to constant 1985 prices using a province-specific rural Consumer Price Index. 


\section{References}

Arellano, M. and S. Bond (1991), "Some Tests of Specification for Panel Data: Monte-Carlo Evidence and An Application to Employment Equation", Review of Economic Studies, 58, 277-298.

Barnow, B., G. Cain and A. Goldberger (1980), "Issues in the Analysis of Selectivity Bias", in E. Stromsdorfer and G. Farkas (eds) Evaluation Studies, Vol. 5.

Barro, Robert and Xavier Sala-i-Martin (1995), Economic Growth, McGraw Hill.

Benabou, Roland (1994), "Human Capital, Inequality, and Growth: A Local Perspective", European Economic Review 38, 817-826.

Besley, Timothy and Anne Case (1994), "Unnatural Experiments? Estimating the Incidence of Endogenous Policies", NBER Working Paper 4956.

Bhargava, Alok and J. Dennis Sargan (1983), "Estimating Dynamic Random Effects Models from Panel Data Covering Short Time Periods", Econometrica, 51, 1635-1659.

Bruno, Michael, Martin Ravallion and Lyn Squire (1995), "Equity and Growth in Developing Countries: Old and New Perspectives on the Policy Issues", Paper presented at IMF Conference on Growth and Distribution.

Chen, Shaohua and Martin Ravallion (1996), "Data in Transition: Assessing Rural Living Standards in Southern China", China Economic Review.

Datt, Gaurav and Martin Ravallion (1993), "Regional Disparities, Targeting, and Poverty in India", in M. Lipton and J. van der Gaag (eds.) Including the Poor, World Bank.

Durlauf, Steven N (1992), "A Theory of Persistent Income Inequality", NBER Working Paper 4056. Hammond, Peter J., and A. Rodriguez-Clare (1993), "On Endogenizing Long-Run Growth", Scandanavian Journal of Economics 95: 391-425. 
Hansen, L. P. (1982), "Large Sample Properties of Generalized Method of Moments Estimators", Econometrica, 50, 1029-1054.

Heckman, J. and R. Robb (1985), "Alternative Methods for Evaluating the Impact of Interventions", in J. Heckman and B. Singer (eds) Longitudinal Analysis of Labor Market Data, Cambridge: Cambridge University Press.

Howes, Stephen and Athar Hussain (1994), "Regional Growth and Inequality in Rural China", Working Paper EF 11, STICERD, London School of Economics.

Hsiao, Cheng (1986), Analysis of Panel Data. Cambridge University Press, New York.

Knight, J. and Song, Lina (1993), "The Spatial Contribution to Income Inequality in Rural China", Cambridge Journal of Economics 17: 195-213.

Leading Group (1988), Outlines of Economic Development in China's Poor Areas, Office of the Leading Group of Economic Development in Poor Areas Under the State Council, Agricultural Publishing House, Beijing.

Lipton, Michael and Martin Ravallion (1995), "Poverty and Policy". In J. Behrman and T.N. Srinivasan (eds) Handbook of Development Economics Volume 3 (Amsterdam: NorthHolland).

Lucas, R.E. (1988), "On the Mechanics of Economic Development", Journal of Monetary Economics, 22: 3-42.

Lyons, T. (1991), "Interprovincial Disparities in China: Output and Consumption, 19521987', Economic Development and Cultural Change, 39(3): 471-506.

Pitt, Mark, Mark Rosenzweig, and Donna Gibbons (1993) "The Determinants and Consequences of the Placement of Government Programs in Indonesia", The World Bank Economic Review, 7: 319-49. 
Ravallion, Martin (1993) "Poverty Alleviation through Regional Targeting: A Case Study for Indonesia", in K. Hoff, A. Braverman, and J.E. Stiglitz (eds) The Economics of Rural Organization, Oxford: Oxford University Press.

Riskin, Carl (1994), "Chinese Rural Poverty: Marginalized or Dispersed?", American Economic Review, Papers and Proceedings, 84(2): 281-284.

Romer, Paul M. (1986) "Increasing Returns and Long-Run Growth", Journal of Political Economy 94: 1002-1037.

Rozelle, Scott (1994),"Rural Industrialization and Increasing Inequality: Emerging Patterns in China's Reforming Economy", Journal of Comparative Economics, 19(3):362-91.

Rosenzweig, Mark R. and K.I. Wolpin (1986), "Evaluating the Effects of Optimally Distributed Public Programs: Child Health and Family Planning Interventions", American Economic Review, 76: 470-82.

Sala-i-Martin, Xavier (1994), "Cross-Sectional Regressions and the Empirics of Economic Growth", European Economic Review, 38: 739-47.

Sargan, J. D. (1958), "The Estimation of Economic Relationships Using Instrumental Variables", Econometrica, 26: 393-415.

Tsui, Kai Yuen (1991), "China's Regional Inequality, 1952-1985", Journal of Comparative Economics, 15: 1-21.

World Bank (1992), China: Strategies for Reducing Poverty in the 1990s, World Bank, Washington DC. 
Table 1: Consumption per person in areas declared poor versus those not

\begin{tabular}{|cccccc|}
\hline Year & $\begin{array}{c}\text { All households } \\
\text { (6651 households) }\end{array}$ & $\begin{array}{c}\text { Not living in areas } \\
\text { declared poor } \\
(4411 \text { households) }\end{array}$ & $\begin{array}{c}\text { Living in areas } \\
\text { declared poor } \\
(2240 \text { households) }\end{array}$ & $\begin{array}{c}\text { Living in } \\
\text { provincial-poor" } \\
\text { areas } \\
\text { (1139 households) }\end{array}$ & $\begin{array}{c}\text { Living in } \\
\text { "national-poor" } \\
\text { areas } \\
\text { (1101 households) }\end{array}$ \\
\hline 1985 & 318.01 & 337.39 & 279.52 & 293.03 & 265.84 \\
& $(327.63)$ & $(360.51)$ & $(223.28)$ & $(227.65)$ & $(213.69)$ \\
1986 & 328.39 & 351.81 & 281.85 & 302.72 & 260.59 \\
& $(354.81)$ & $(384.15)$ & $(253.76)$ & $(270.91)$ & $(223.40)$ \\
1987 & 342.81 & 368.94 & 290.97 & 313.15 & 268.47 \\
& $(384.39)$ & $(411.71)$ & $(285.99)$ & $(328.02)$ & $(222.14)$ \\
1988 & 344.17 & 371.10 & 290.51 & 313.75 & 267.12 \\
& $(387.16)$ & $(417.92)$ & $(276.89)$ & $(309.76)$ & $(224.77)$ \\
1989 & 344.20 & 373.54 & 285.98 & 313.37 & 258.18 \\
& $(419.45)$ & $(449.67)$ & $(309.35)$ & $(354.00)$ & $(237.59)$ \\
1990 & 340.80 & 370.77 & 281.12 & 305.19 & 256.51 \\
& $(428.11)$ & $(467.49)$ & $(290.58)$ & $(331.22)$ & $(227.45)$ \\
\hline
\end{tabular}

Note: In Yuan per person per year in 1985 prices, with standard deviations in parentheses. 
Table 2: Comparison of consumption per person in Guangdong with Guangxi, Guizhou and Yunnan

\begin{tabular}{|c|c|c|c|c|c|c|}
\hline \multirow[t]{2}{*}{ Year } & \multicolumn{2}{|c|}{$\begin{array}{c}\text { Guangdong } \\
(1,604 \text { households })\end{array}$} & \multirow[b]{2}{*}{$\begin{array}{l}\text { Not living in areas } \\
\text { declared poor } \\
(3,148 \text { households) }\end{array}$} & \multicolumn{2}{|c|}{$\begin{array}{c}\text { Guangxi, Guizhou and Yunnan } \\
(5,047 \text { households })\end{array}$} & \multirow[b]{2}{*}{$\begin{array}{l}\text { Living in areas } \\
\text { declared provincial } \\
\text { poor (798 households) }\end{array}$} \\
\hline & $\begin{array}{c}\text { Not living in areas } \\
\text { declared poor } \\
(1,263 \text { households }) \\
\end{array}$ & $\begin{array}{c}\text { Living in areas } \\
\text { declared poor } \\
\text { (341 households) }\end{array}$ & & $\begin{array}{l}\text { Living in areas } \\
\text { declared poor } \\
\text { (1,899 households) }\end{array}$ & $\begin{array}{l}\text { Living in areas declared } \\
\text { "national" poor } \\
\text { (1101 households) }\end{array}$ & \\
\hline 1985 & $\begin{array}{c}429.38 \\
(467.98)\end{array}$ & $\begin{array}{c}339.51 \\
(241.33)\end{array}$ & $\begin{array}{c}300.14 \\
(257.08)\end{array}$ & $\begin{array}{c}268.64 \\
(209.51)\end{array}$ & $\begin{array}{c}265.84 \\
(213.69)\end{array}$ & $\begin{array}{c}272.63 \\
(203.34)\end{array}$ \\
\hline 1986 & $\begin{array}{c}475.95 \\
(472.59)\end{array}$ & $\begin{array}{c}380.66 \\
(301.02)\end{array}$ & $\begin{array}{c}301.42 \\
(256.87)\end{array}$ & $\begin{array}{c}264.00 \\
(218.33)\end{array}$ & $\begin{array}{c}260.59 \\
(223.40)\end{array}$ & $\begin{array}{c}268.79 \\
(210.75)\end{array}$ \\
\hline 1987 & $\begin{array}{c}500.19 \\
(503.75)\end{array}$ & $\begin{array}{c}413.69 \\
(397.01)\end{array}$ & $\begin{array}{c}315.51 \\
(281.06)\end{array}$ & $\begin{array}{l}268.88 \\
(223.41)\end{array}$ & $\begin{array}{l}268.47 \\
(222.14)\end{array}$ & $\begin{array}{c}269.45 \\
(225.28)\end{array}$ \\
\hline 1988 & $\begin{array}{c}482.67 \\
(494.89)\end{array}$ & $\begin{array}{c}408.74 \\
(341.48)\end{array}$ & $\begin{array}{c}325.26 \\
(324.71)\end{array}$ & $\begin{array}{c}269.20 \\
(229.59)\end{array}$ & $\begin{array}{c}267.12 \\
(224.77)\end{array}$ & $\begin{array}{c}272.19 \\
(236.04)\end{array}$ \\
\hline 1989 & $\begin{array}{c}501.05 \\
(594.09)\end{array}$ & $\begin{array}{c}429.67 \\
(436.12)\end{array}$ & $\begin{array}{c}320.46 \\
(297.06)\end{array}$ & $\begin{array}{c}260.01 \\
(232.69)\end{array}$ & $\begin{array}{c}258.18 \\
(237.59)\end{array}$ & $\begin{array}{c}262.60 \\
(225.76)\end{array}$ \\
\hline 1990 & $\begin{array}{c}515.18 \\
(598.21)\end{array}$ & $\begin{array}{c}410.05 \\
(410.95)\end{array}$ & $\begin{array}{c}310.01 \\
(307.07)\end{array}$ & $\begin{array}{c}257.71 \\
(325.34)\end{array}$ & $\begin{array}{c}256.51 \\
(227.45)\end{array}$ & $\begin{array}{c}259.39 \\
(216.88)\end{array}$ \\
\hline
\end{tabular}

Note: In Yuan per person per year in 1985 prices, with standard deviations in parentheses. 
Table 3: GMM estimates

\begin{tabular}{|c|c|c|c|}
\hline \multicolumn{2}{|l|}{ Variable } & Coefficient & t-statistic \\
\hline \multicolumn{2}{|l|}{ Constant } & -0.21486 & -6.09 \\
\hline \multicolumn{2}{|c|}{ Lagged dependent variable } & 0.10790 & 1.68 \\
\hline \multicolumn{2}{|c|}{ Change in (log) county yield } & 0.29765 & 3.50 \\
\hline \multicolumn{2}{|c|}{ Lagged change in (log) county yield } & 0.36090 & 4.13 \\
\hline \multicolumn{2}{|c|}{ Change in household size } & -0.16223 & -2.87 \\
\hline \multicolumn{2}{|c|}{ Lagged change in household size } & -0.06209 & -0.91 \\
\hline \multicolumn{2}{|c|}{ Declared national poor county } & 0.01217 & 2.71 \\
\hline \multicolumn{2}{|c|}{ Declared provincial poor county } & -0.00374 & -0.92 \\
\hline \multicolumn{2}{|c|}{ Initial (log) average county wealth per capita } & 0.04303 & 7.84 \\
\hline \multicolumn{2}{|c|}{ Initial (log) household wealth per capita } & -0.00901 & -3.11 \\
\hline \multicolumn{2}{|c|}{ Fertilizer usage (county) per sq $\mathrm{km}$ of cultivated area, 1985} & 0.00026 & 0.90 \\
\hline \multicolumn{4}{|c|}{ Province interacted time-dummies } \\
\hline \multicolumn{2}{|c|}{ Guangdong 1988} & -0.06954 & -5.90 \\
\hline " " & 1989 & -0.03233 & -2.23 \\
\hline$" n$ & 1990 & -0.07565 & -4.48 \\
\hline Guangxi & 1987 & 0.042834 & 3.80 \\
\hline " " & 1988 & 0.00802 & 0.50 \\
\hline " " & 1989 & -0.10712 & -7.61 \\
\hline$n "$ & 1990 & -0.12385 & -4.27 \\
\hline Guizhou & 1987 & 0.03283 & 2.15 \\
\hline " " & 1988 & 0.06429 & 3.64 \\
\hline$" "$ & 1989 & -0.04506 & -3.05 \\
\hline$n "$ & 1990 & -0.06959 & -3.08 \\
\hline Yunnan & 1987 & -0.00895 & -0.64 \\
\hline " " & 1988 & -0.06088 & -3.79 \\
\hline$n "$ & 1989 & -0.00262 & -0.16 \\
\hline " " & 1990 & -0.10910 & -6.47 \\
\hline Second 0 & ler serial correlation test statistic & 0.3 & \\
\hline $\begin{array}{l}\text { Sargan-H } \\
\text { (degrees }\end{array}$ & $\begin{array}{l}\text { nsen overidentification test statistic } \\
\text { freedom in parentheses) }\end{array}$ & $\begin{aligned} 15 . \\
\text { (d.f. }\end{aligned}$ & \\
\hline
\end{tabular}

Notes: The dependent variable is the first difference of the log of consumption per capita. The instruments used for lagged consumption per capita, current and lagged yield variables and current household size were $c_{i t-2}$ (one moment condition), yield $\mathrm{it}_{\mathrm{t}-2}$ (one moment condition) and lagged household size (one moment condition). 
Figure 1: Mean consumptions in areas targeted by the program and those not

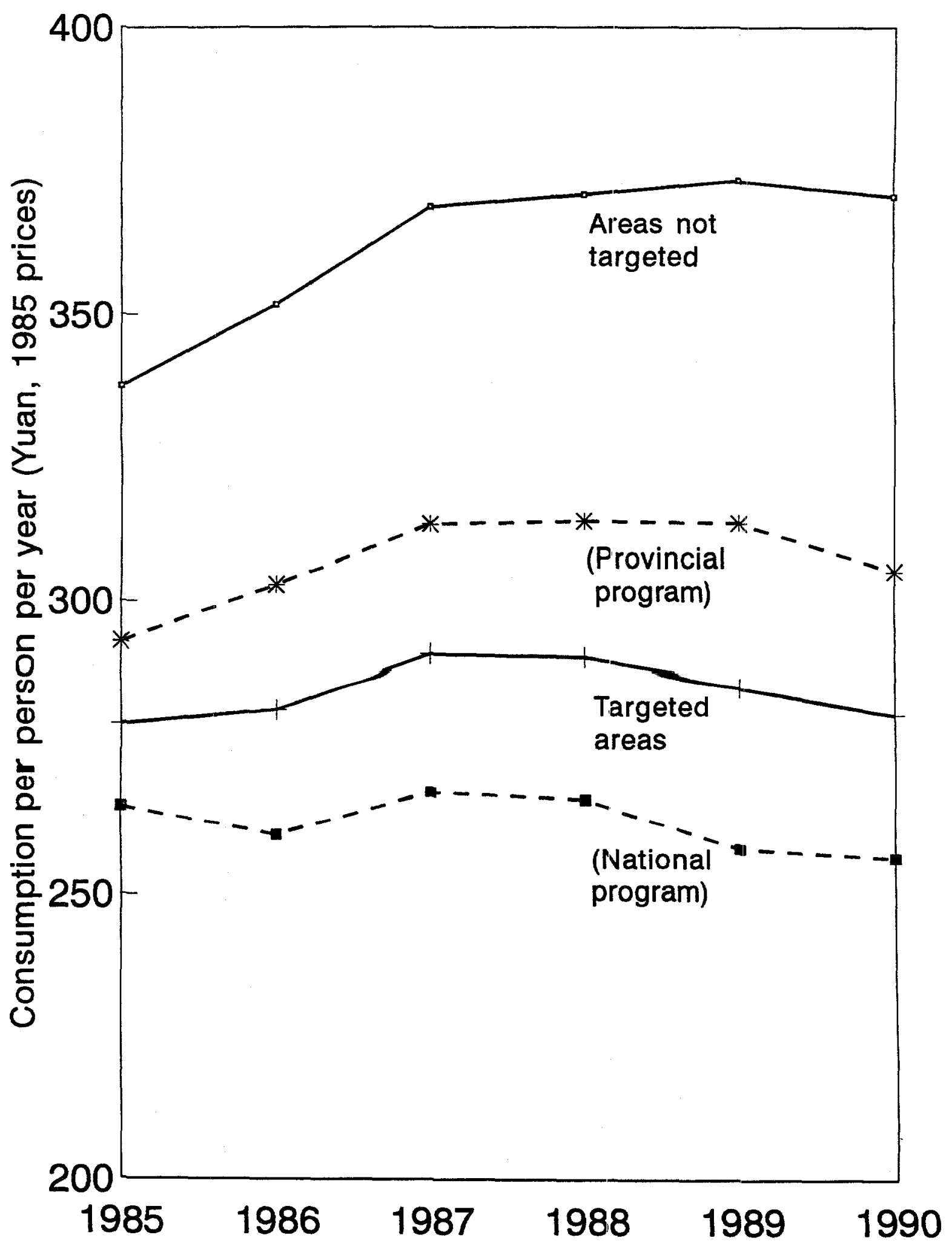




\section{Policy Research Working Paper Series}

Title

Author

WPS1678 Financial Development and Economic Ross Levine

Growth: Views and Agenda

WPS1679 Trade and the Accumulation and Diffusion of Knowledge

WPS1680 Brazil's Efficient Payment System: A Legacy of High Inflation

WPS1681 India in the Global Economy

WPS1682 is the "Japan Problem" Real? How Problems in Japan's Financial Sector Could Affect Developing Regions

WPS1683 High Real Interest Rates, Guarantor Risk, and Bank Recapitalizations

WPS1684 The Whys and Why Nots of Export Taxation

WPS1685 Macroeconomic Crises and Poveriy Monitoring: A Case Study for India

WPS1686 Institutions, Financial Markets, and Firms' Choice of Debt Maturity

WPS1687 Regionalism versus Multilateralism

WPS1688 Risk, Taxpayers, and the Role of Government in Project Finance

WPS1689 is Economic Analysis of Projects Stiil Useful?

WPS1690 Stock Markets, Banks, and Economic Growth

WPS 1691 Integrating the Unofficial Economy into the Dynamics of Post-Socialist Economies: A Framework of Analysis and Evidence
Pier Carlo Padoan

Robert Listfield

Fernando Montes-Negret

Milan Brahmbhatt

T. G. Srinivasan

Kim Murrell

Shigeru Otsubo

Masahiko Tsutsumi

Philip L. Brock

Shantayanan Devarajan

Delfin Go

Maurice Schiff

Sethaput Suthiwart-Narueput

Gaurav Datt

Martin Ravallion

Asli Demirgüç-Kunt

Vojislav Maksimovic

L. Alan Winters

Michael Klein

Pedro Belli

Ross Levine

Sara Zervos

Daniel Kaufmann

Aleksander Kaliberda
Date

October 1996

November 1996

November 1996

November 1996

November 1996

November 1996

November 1996

November 1996

December 1996

December 1996

December 1996

December 1996
J. Queen 33740 37699

P. Sader 33902

Contact for paper

P. Sintim-Aboagye 38526

M. Pateña 39515

$T$. Ishibe 38968

S. Crow 30763

N. Castillo 33490

P. Sintim-Aboagye 37644

A. Kitson-Walters 33712

S. Vivas 82809

K. Schrader 82736

$P$. Sintim-Aboagye 38526

S. Torres 39012 


\section{Policy Research Working Faper Series}

Title

WPS1692 Regulating Market Risk in Banks: A Comparison of Alternative Regulatory Regimes

WPS1693 Famines and Economics

WPS1694 What Can New Survey Data Tell Us Martin Ravallion about Recent Changes in Distribution Shaohua Chen and Poverty?

WPS1695 Are There Dynamic Gains from a Poor-Area Development Program?
Author

Constantinos Stephanou

Martin Ravallion

Jyotsna Jalan

Martin Ravaltion
Contact

Date for paper

December 1996

P. Infante

37642

December 1996

December 1996

A. Ramirez 85734

A. Ramirez 85734

December 1996

A. Ramirez 85734 